\title{
Management of Soil Constraints to Improve Crop Performance in Water-Limited Environments
}

\author{
Geoffrey C. Anderson *(D) and Edward G. Barrett-Lennard \\ Department of Primary Industries and Regional Development, 75 York Road, Northam, WA 6401, Australia; \\ Ed.Barrett-Lennard@dpird.wa.gov.au \\ * Correspondence: Geoff.Anderson@dpird.wa.gov.au
}

Citation: Anderson, G.C.; Barrett-Lennard, E.G. Management of Soil Constraints to Improve Crop Performance in Water-Limited Environments. Agronomy 2021, 11, 2558. https://doi.org/10.3390/ agronomy11122558

Received: 24 November 2021 Accepted: 14 December 2021 Published: 16 December 2021

Publisher's Note: MDPI stays neutral with regard to jurisdictional claims in published maps and institutional affiliations.

Copyright: (c) 2021 by the authors. Licensee MDPI, Basel, Switzerland. This article is an open access article distributed under the terms and conditions of the Creative Commons Attribution (CC BY) license (https:/ / creativecommons.org/licenses/by/ $4.0 /)$.
One current challenge for agricultural production in water-limited environments is to develop agronomic management practices that can overcome soil constraints and provide an economic return to the grower in both the short and long-term. The soil constraints acidity/aluminum ( $\mathrm{Al})$ toxicity, compaction, water repellency, salinity, and poor nutrition result in reduced crop grain yield in these environments. The Special Issue "Management of Soil Constraints to Improve Crop Performance in Water-Limited Environments" provides a series of 7 papers addressing these issues with conventional, evolving, and novel management practices. These management practices include the application of lime and gypsum in the case of acidity and Al toxicity [1-5]; inversion tillage to remove multiple constraints of compaction and water repellence and comparisons with modified seeding equipment, the addition of clay and soil wetters that ameliorate water repellency [6]; water harvesting and the application of gypsum in the case of salinity [7]; and the application of nutrients $[1,5,6]$. Often these soil constraints can occur together, which requires management practices that remove multiple soil constraints [5,6]. In addition, removing the most limiting soil constraint can improve the efficiency of other inputs or the supply of nutrients $[5,6]$.

Scientists use soil chemical and physical measurements to determine the severity of the constraint. Common soil measurements include soil extract techniques that measure nutrient status, acidity/alkalinity, Al toxicity [1-7], and soil salinity [7], the ethanol droplet test (which measures water repellence) [6], the penetrometer test (which measures soil strength [6]. Using this knowledge, treatments or management practices are selected that are likely to overcome these soil constraints.

The soil $\mathrm{pH}$ and $\mathrm{Al}$ measurements are used to identify the limitation imposed by soil acidity and $\mathrm{Al}$ toxicity [1-6]. The application of lime increases crop grain yield response at soil $\mathrm{pH}$ measured by $0.01 \mathrm{M} \mathrm{CalCl}_{2}\left(\mathrm{pH}_{\mathrm{CaCl}_{2}}\right)$ values $<5.0$ in the $0-10 \mathrm{~cm}$ soil layer

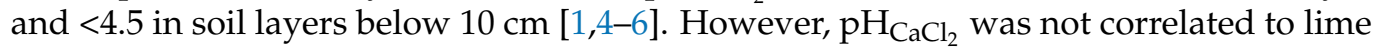
response and can only be used as a guide for a lime response [4]. Indicating a more accurate measurement of the soil acidity constraint is required than using $\mathrm{pH}_{\mathrm{CaCl}_{2}}$. Also, Anderson et al. [2] illustrated lime and gypsum application had a greater impact on soil $\mathrm{Al}$ measured by $0.01 \mathrm{M} \mathrm{CalCl}_{2}$ solution $\left(\mathrm{Al}_{\mathrm{CaCl}_{2}}\right)$ than the changes observed in $\mathrm{pH}_{\mathrm{CaCl}_{2}}$. Hence, changes in $\mathrm{Al}_{\mathrm{CaCl}_{2}}$ is a more sensitive measurement of the impacts of lime and gypsum than changes in $\mathrm{pH}_{\mathrm{CaCl}_{2}}[2,4]$.

The movement of surface-applied lime into the subsoil is often slow [1-4], especially in conservation farming systems (e.g., no-till and crop residue retention). In this farming system, limited soil disturbance can restrict lime dissolution resulting in the slow movement of alkalinity dissolved into the soil layers below $10 \mathrm{~cm}$. Hence, the grain yield obtained for the 'plus lime' treatments is often less than the potential water-limited grain yield [4]. Oliver et al. [4] overcame this limitation by using the Agricultural Production Systems sIMulator (APSIM) to define potential yield and restriction imposed by $\mathrm{Al}$ toxicity on root growth $(\mathrm{xf})$ to obtain grain yield increase relative to potential grain yield (RYI). As 
a result, the size of the lime response, as measured by RYI (ranging between 17-34\%), was greater than observed using the grain yield (13-17\%). In addition, a more soluble product is required to impact subsoil $\mathrm{Al}$ toxicity. Gypsum is 192 times more soluble than lime enabling the dissolved sulfate $\left(\mathrm{SO}_{4}-\mathrm{S}\right)$ and calcium $(\mathrm{Ca})$ to be leached into the soil profile to reduce the subsoil $\mathrm{Al}$ toxicity and increase crop grain yield [1]. The effect of lime and gypsum application on soil chemistry is complex, and chemical and solution studies combined with chemical equilibrium models are required to explain the mechanism for the observed crop response [2,3].

Soil acidification is a natural process accelerated by removing agricultural products and applying nitrogen fertilizers, resulting in declining agricultural production and soil $\mathrm{pH}$ values and an associated increase in $\mathrm{Al}$ toxicity [5]. Nutrient removal associated with crop production decreases soil fertility, particularly in the absence of fertilizer use $[1,5,6]$. The development of acid soils results in reduced nitrogen use efficiency [5], while the application of lime results in increased molybdenum uptake [1]. Application of clay to treat water repellence can result in an increased supply of potassium [6]. However, an additional potassium fertilizer application is required to provide a positive potassium balance to maintain the site's productivity [6]. Once the soil has become acidic, soil surface application of lime can begin to reverse the effect [1,4,5]. However, it requires the application of high rates, which take time to impact the soil $\mathrm{pH}$ and improve the crop grain productivity $[1,4,5]$.

Water repellence limitation on crop production occurs when the molarity of the ethanol droplet test is $>3$ [6]. This generally occurs in soils with clay contents of $<5 \%$, where sand particles become coated with naturally occurring organic waxes and polymers. Soil compaction also appears in these soils both naturally and by running heavy farm equipment over the soil. The degree of soil compaction is obtained by measuring soil strength using a soil penetrometer with soil having cone index readings of $>1500 \mathrm{kPa}$ having restricted root growth. Hall et al. [6] illustrated the importance of undertaking both measurements, demonstrating water repellency could be partially managed at a relatively low cost using modified seeding tynes. However, more expensive cultivation practices such as mouldboard ploughing and spading can be cost-effective in treating these multiple constraints.

Soil dispersion occurs due to the combined effect of soil sodicity, soil with exchangeable sodium percentage (ESP) of greater than $6 \%$ and soil with $\mathrm{pH}$ values greater than 8.5 [7]. The effect of dispersive soils, which are sodic and alkaline in semi-arid environments and have poor drainage properties result in the accumulation of salts, referred to as "transient salinity". The expression of "transient salinity" in semi-arid environments is the reduced availability of stored water due to osmotic and ion toxicity stresses on plant roots. Increased crop productivity is hypothesized to occur by increasing soil hydration and leaching salt. Using these concepts, micro-water harvesting and gypsum or elemental sulfur application increased barley grain yield by $57-70 \%$ due to the soil profile's decreased salinity over the two-year study period [7].

Dry seasonal conditions result in a greater expression of the management solution to acidity / $\mathrm{Al}$ toxicity and water repellence in a water limited-environment $[1,4,6]$. Both Anderson et al. [1] and Oliver et al. [4] showed the greatest response to lime application occurs under seasonal conditions where crop growth is more dependent on the subsoil water supply. This happened under seasonal conditions of high summer rainfall followed by low growing season rainfall compared to average growing season rainfall with small amounts of summer rainfall. Similarly, the expression of water repellence is most significant under dry seasonal conditions, which result in poor crop establishment [6].

In assessing the performance of the management practice, it is essential to consider the cost of the treatment because the management practices may overcome the limitation, but the grain yield benefit obtained may not cover the cost of the treatment [1,6]. In other cases, the economic management practice may not be known, and more fundamental research is required to understand the soil processes that impact crop production $[2,3,7]$. Furthermore, 
it is essential to consider the longevity of management practices in overcoming [1,4-6] or the rate of development of the soil constraint [5]. Hence, the long-term economic gain to be made from intervention may not be evident from short-term experiments. For example, the benefit of lime application lasts a long-time, especially in low rainfall zone due to the slow rate of soil acidification [1,2,4]. Also, the slow accumulation of surface soil organic carbon following mouldboard ploughing and spading will result in long-term benefits outside of the experimental period. In contrast, short-term treatment effects, application of gypsum, still important because they remove the soil constraint, which is not achieved by the long-term management practice, application of lime [1]. In addition, Anderson et al. [2] observed the short-term treatment of applying gypsum can increase the effectiveness of long-term applying lime.

Author Contributions: G.C.A. and E.G.B.-L. wrote this editorial introduction of the Special Issue of Agronomy, entitled "Management of Soil Constraints to Improve Crop Performance in Water-Limited Environments", and edited the Special Issue. All authors have read and agreed to the published version of the manuscript.

Funding: Department of Primary Industries and Regional Development funded G.C.A. and E.G.B.-L. to write this article.

Acknowledgments: We are grateful to all authors who submitted their valuable manuscripts to the Special Issue of Agronomy, entitled "Management of Soil Constraints to Improve Crop Performance in Water-Limited Environments".

Conflicts of Interest: The authors declare no conflict of interest.

\section{References}

1. Anderson, G.C.; Pathan, S.; Easton, J.; Hall, D.J.M.; Sharma, R. Short- and long-term effects of lime and gypsum application on acid soils in a water-limited environment: 1. Grain yield response and nutrient concentration. Agronomy 2020, 10, 1213. [CrossRef]

2. Anderson, G.C.; Pathan, S.; Easton, J.; Hall, D.J.M. Sharma R Short and long-term effects of lime and gypsum application on acid soils in a water-limited environment: 2. Soil chemical properties. Agronomy 2020, 10, 1987. [CrossRef]

3. Anderson, G.C.; Pathan, S.; Easton, J.; Hall, D.J.M. Sharma R Short and long-term effects of lime and gypsum application on acid soils in a water-limited environment: 3. Soil solution chemistry. Agronomy 2021, 11, 826. [CrossRef]

4. Oliver, Y.M.; Gazey, C.; Fisher, J.; Robertson, M. Dissection of the Contributing Factors to the Variable Response of Crop Yield to Surface Applied Lime in Australia. Agronomy 2021, 11, 829. [CrossRef]

5. Daba, N.A.; Li, D.; Huang, J.; Han, T.; Zhang, L.; Ali, S.; Khan, M.N.; Du, J.; Liu, S.; Legesse, T.G.; et al. Long-Term Fertilization and Lime-Induced Soil pH Changes Affect Nitrogen Use Efficiency and Grain Yields in Acidic Soil under Wheat-Maize Rotation. Agronomy 2021, 11, 2069. [CrossRef]

6. Hall, D.J.M.; Davies, S.L.; Bell, R.W.; Edwards, T.J. Soil Management Systems to Overcome Multiple Constraints for Dryland Crops on Deep Sands in a Water Limited Environment on the South Coast of Western Australia. Agronomy 2020, $10,1881$. [CrossRef]

7. Barrett-Lennard, E.G.; Munir, R.; Mulvany, D.; Williamson, L.; Riethmuller, G.; Wesley, C.; Hall, D. Micro-Water Harvesting and Soil Amendment Increase Grain Yields of Barley on a Heavy-Textured Alkaline Sodic Soil in a Rainfed Mediterranean Environment. Agronomy 2021, 11, 713. [CrossRef] 